\title{
Prevalence and Mortality Incidence of Poisoning Cases in Serdang Hospital
}

\author{
Tan Hooi Leng1*, Haizun Athirah Ismail ${ }^{1}$, Heng Li Xuan², Koh Liang Zhengㄹ, Nur Anis Ahmad Lotfi3 \\ and Nur Syazwani Taridi ${ }^{1}$ \\ ${ }^{1}$ Department of Pharmacy, Serdang Hospital, Jalan Puchong 43000 Kajang, Selangor \\ ${ }^{2}$ Department of Pharmacy, Selayang Hospital, Lebuhraya Selayang-Kepong, 68100 Batu Caves, Selangor \\ 3Department of Pharmacy, Klinik Kesihatan Sijangkang, Jalan Sekolah, Batu 1, \\ Kg Sijangkang 42500 Banting, Kuala Langat Selangor
}

\begin{abstract}
In Malaysia, there were more than 35,000 poisoning cases enquiries were reported to the poison centre since its establishment from the year 1995 to 2014. The objective of our study is to determine the prevalence of poisoning cases and antidote used in Serdang Hospital. All poisoning cases admitted to the Serdang Hospital between January 2007 to December 2016 were evaluated retrospectively by using consecutive sampling. Data were obtained from Electronic Hospital Information System (eHIS) by using data collection form. Descriptive statistic was used to analyse the data. 903 patients were included in our study. The prevalence of poisoning cases during the study period is $0.22 \%$. The fatality rate was $1.8 \%(n=16)$. More detailed data reveals that young adults aged between 18 to 29 years old, $44.2 \%(n=399)$ has the preponderance of poisoning cases, and females, 59.7\% ( $\mathrm{n}=539)$ admission dominated over males. Most poisoning cases were intentional, 74.5\% $(n=673)$ and related to the use of non-opioid analgesics, 35.7\% $(n=322)$. In summary, these trends of poisonings provides a foundation to recognise areas for training and education on self-injury prevention among healthcare providers and public society.
\end{abstract}

Keywords: poisoning; prevalence; antidotes; fatality; intentional

\section{INTRODUCTION}

A study conservatively estimated about 258,234 (approximately 233,997 to 325,907 ) deaths from pesticide self-poisoning globally each year (David Gunnell, Michael Eddleston, 2007). In 2004, data showed 346,000 deaths from unintentional poisoning worldwide. (WHO, "Poisoning prevention and management, 2012).

An estimation from data of a few countries in Asia suggested that about 300,000 suicides by intentional ingestion of pesticides every year (Gunnell D, 2003) (Buckley NA et al., 2004). A study reported poisoning in Bangladesh comprises about $44 \%$ of all deaths in females and about 8 to $10 \%$ of overall mortality in medical wards of tertiary healthcare settings (Chowdhury FR et al., 2011). On the other hand, Ramathibodi Poison Centre in Thailand has reported throughout the year 2001 to 2004, the rate of acute poisoning averaged 6 per 100,000 persons annually. Although the reported poisoning incidence was low, the rate has consistently increased from 3.2 to 9.1 over the four years (W. Wananukul et al., 2007).

A retrospective review of poisoning cases admitted to a teaching hospital in Malaysia between year 1987 and 1995 reported poisoning admissions contributed to $0.2 \%$ of total admissions (Ab Rahman, 2002). According to another retrospective study on poisoning admissions to all government health settings in Malaysia from the year 1999 to 2001, the report showed 21714 admissions with 779 deaths. The case-fatality rate was $35.88 / 1000$ admissions 
(Rajasuriar et al., 2007). A statistic revealed by the National Poison Centre of Malaysia showed a record of 3057 poisoning exposures from the year 2001 to 2005, in an increasing trend annually. The increment was significant after the year 2003.

Knowing the patterns of poisonings will provide a foundation for the recognition of areas where training and education may be required. The objective of this study is to identify the types of poisoning, antidotes used, and to determine their survival and health complications.

\section{MATERIALS AND METHOD}

This retrospective observational study was performed using healthcare records obtained from Serdang Hospital. Serdang Hospital is a tertiary care hospital which covers patients from Serdang, Bangi, Putrajaya, Kajang, Dengkil and Puchong area. This study was approved by the National Medical Research Secretariat (NMRR ID-NMRR-18-1014-40060). This study adhered to strict information governance and security protocols.

This study included poisoning cases that were admitted to the Serdang Hospital emergency department (ED) between $1^{\text {st }}$ January 2007 and $31^{\text {st }}$ December 2016. Consecutive sampling method was used. A poisoning event is defined as an emergency hospital admission with a diagnosis of poisoning using codes of the International Statistical Classification of Disease and Related Health Problems, $10^{\text {th }}$ revision (ICD-10 T36-T65) (Appendix 1) except poisoning admission due to food poisoning (code T61 and T62) and deceased patients who brought in to ED were excluded.
A data collection form was used, and it was divided into three sections. Patients' demographic data which include gender, age and ethnic group, were collected and documented in the first section of the form. The second section of the form was to extract details of poisoning such as route of poisoning (ingestion, injection, inhalation, topical), nature of poisoning (intentional, accidental), types of poisoning (based on ICD10 codes), day of hospitalisation and management of poisoning whereas the data on treatment outcome was recorded in the third section of the data collection form.

Patients' survival was further divided into survival with full recovery and survival with health complications. Health complications were defined as any form of permanent adverse health effect that is due to poisoning.

Categorical variables were tabulated using proportion (\%) whereas continuous variables were tabulated using median with standard deviation. Data were analysed using Statistical Package for the Social Sciences (SPSS) for Windows, version 21.0.

\section{RESULT AND DISCUSSION}

Of the 1058 admission to the emergency department in Serdang Hospital, traceable via eHIS, 903 patients were included (Figure 1). Baseline characteristics are shown in Table 1. Of these 903 patients, females dominated over males, the highest incidence rate covers the age range from 18 to 29 years, and Malay patients accounted for most of the admission cases.

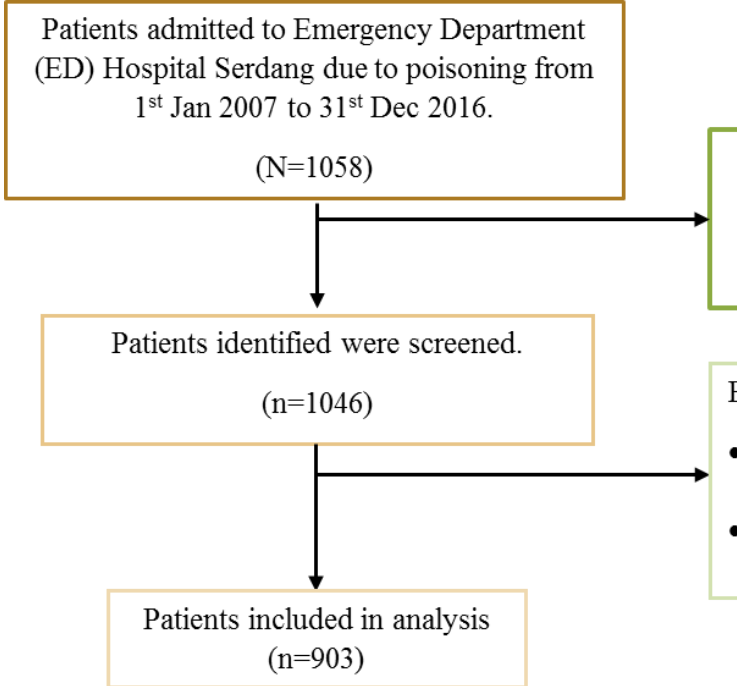

Patients admitted due to food poisoning were excluded.

$$
(n=12)
$$

Excluded patients

- who were deceased prior to ED admission. $(\mathrm{n}=11)$

- $\quad$ whose diagnosis were recorded with the wrong ICD-10 code $(n=132)$

Figure 1. Flow Diagram 
Table 1. Baseline Characteristics

\begin{tabular}{|c|c|}
\hline Characteristics & All Patient $(\mathrm{N}=903)$ \\
\hline \multicolumn{2}{|l|}{ Gender } \\
\hline Male & $364(40.3)$ \\
\hline Female & $539(59.7)$ \\
\hline \multicolumn{2}{|l|}{ Age } \\
\hline$<12$ years old & $127(14.1)$ \\
\hline $12 \quad 12-17$ years old & $78(8.6)$ \\
\hline $18 \quad 18-29$ years old & $398(44.1)$ \\
\hline $30-39$ years old & $171(18.9)$ \\
\hline $40-49$ years old & $69(7.6)$ \\
\hline $50-59$ years old & 27 (3.0) \\
\hline$>60$ years old & $33(3.7)$ \\
\hline \multicolumn{2}{|l|}{ Race } \\
\hline Malay & $344(38)$ \\
\hline Chinese & $155(17.2)$ \\
\hline Indian & $305(33.8)$ \\
\hline Others & 99 (11.0) \\
\hline
\end{tabular}

Note: All values are reported as no (\%) unless otherwise noted.

The general characteristics of poisoning cases are shown in animal, and antileptics (Figure 2). On the other hand, the top Table 2. Intentional poisoning was the commonest and 5 uses of antidote in our study were activated charcoal, poisoning by ingestion was the highest route of poisoning acetylcysteine, flumazenil, atropine and pralidoxime (Figure reported. The highest five types of poisoning in this study 3).

were non-opioid analgesics, pesticides, venomous plants and

Table 2. General Characteristics

\begin{tabular}{|l|l|}
\hline \multicolumn{1}{|c|}{ Characteristics } & \multicolumn{1}{c|}{$\begin{array}{c}\text { All patients } \\
\text { (N=903) }\end{array}$} \\
\hline $\begin{array}{l}\text { Route of Poisoning } \\
\text { Ingestion }\end{array}$ & $814(90.1)$ \\
Injection & $2(0.2)$ \\
Inhalation & $14(1.6)$ \\
Topical & $1(0.1)$ \\
Others & $72(8.0)$ \\
\hline Nature of Poisoning & \\
Accidental & $230(25.5)$ \\
Intentional & $673(74.5)$ \\
\hline
\end{tabular}

Note: All values are reported as no (\%) unless otherwise noted. 


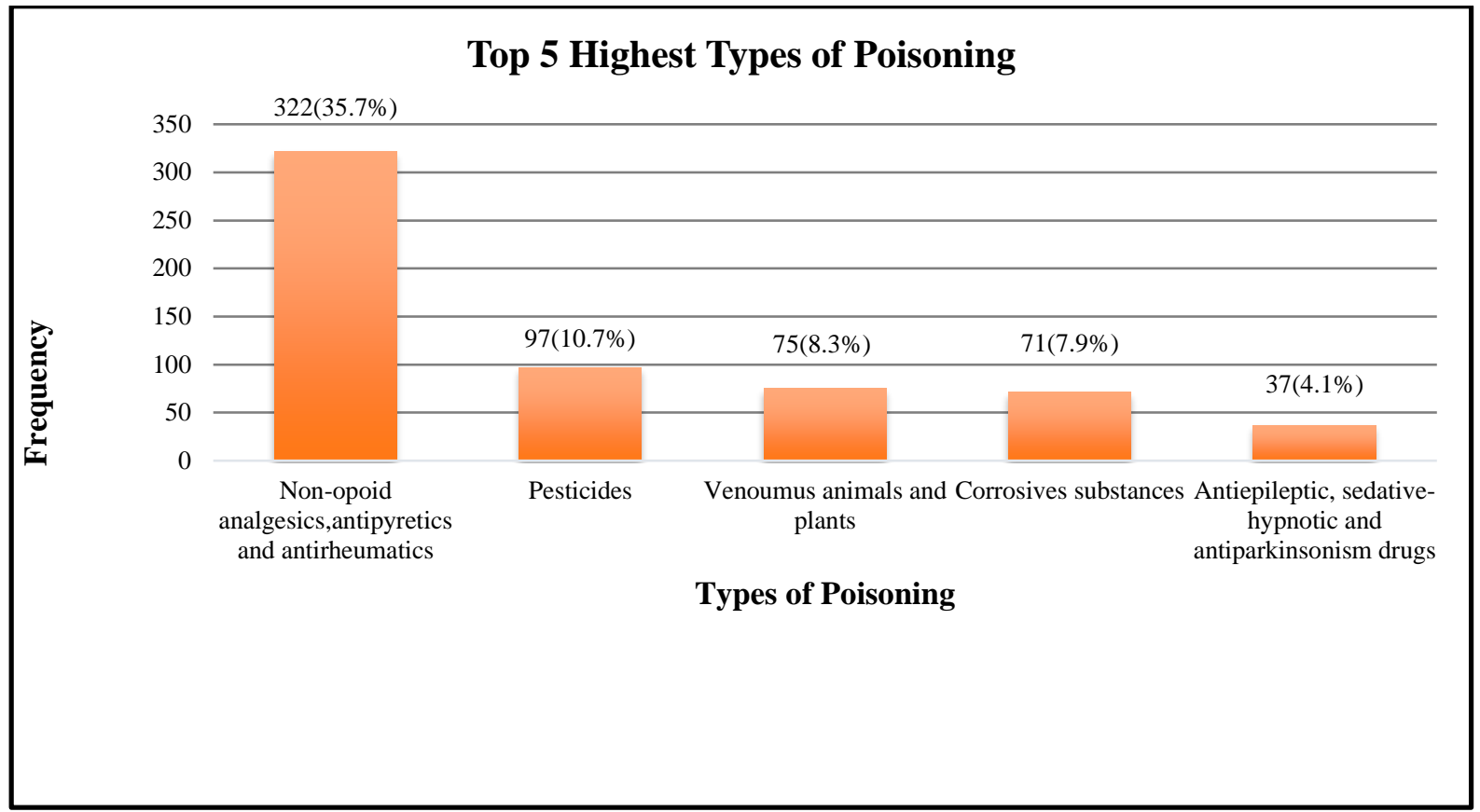

Figure 2. Top 5 Highest Type of Poisoning over 10 years

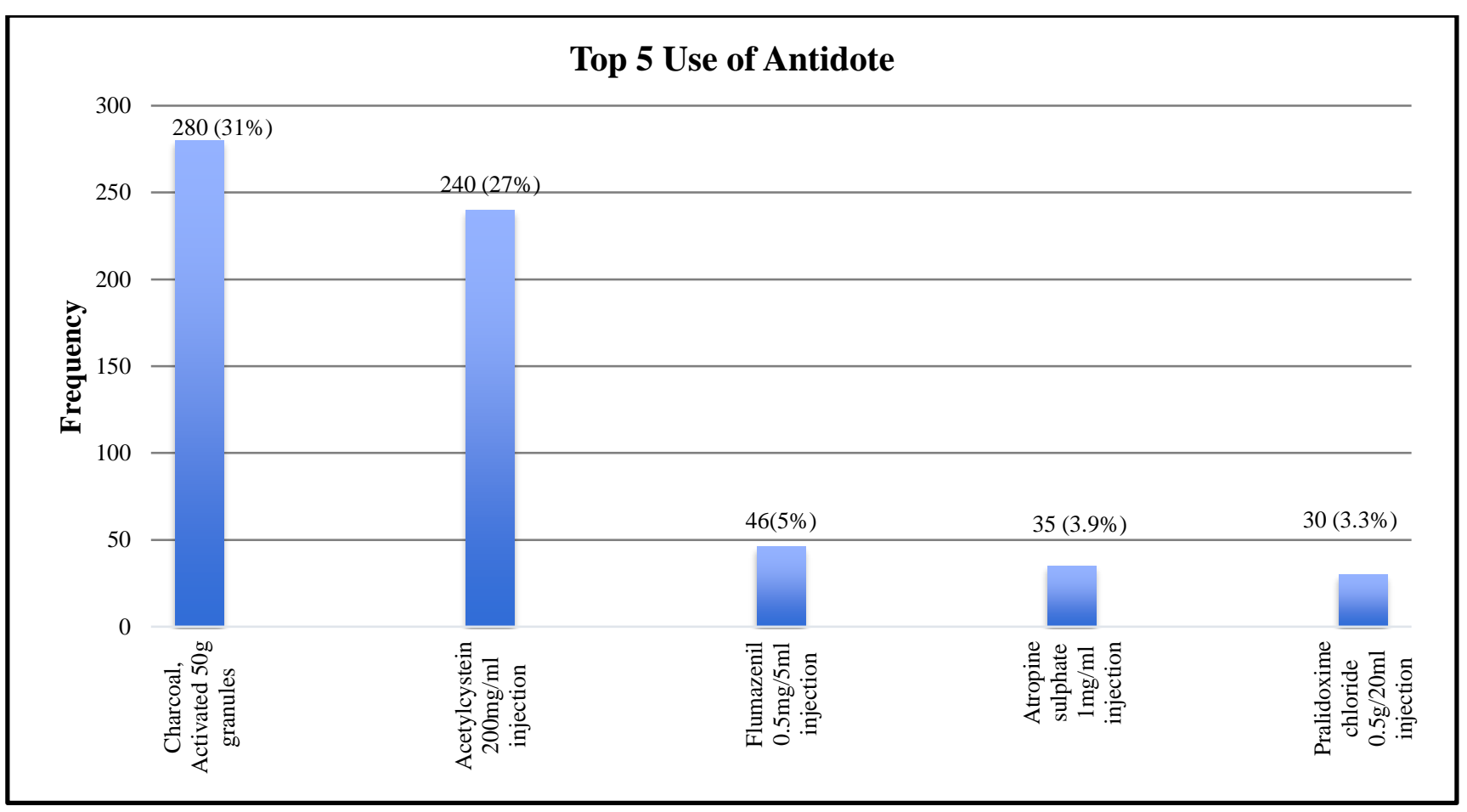

Figure 3. Top 5 Antidote Use over 10 years 
The poisoning related fatality is shown in Table 3. In this The prevalence of poisoning cases from $1^{\text {st }}$ Jan 2007 until study, most of the patients survived with full recovery. $31^{\text {st }}$ Dec 2016 showed decreasing in trend at which the highest Pesticides (ICD-10 Code T60) were one of the major and the least number of cases occurred in the year 2007 and contributors to the poisoning cases in the study which caused 2014 respectively (Figure 4).

most of the fatalities, followed by alcohol with ICD-Code $\mathrm{T}_{51}$, narcotics \& psychodysleptic's with ICD-10 Code T46.

Table 3. Poisoning Related Fatality

\begin{tabular}{|c|c|c|c|c|}
\hline \multicolumn{5}{|c|}{ Treatment Outcome } \\
\hline & $\begin{array}{l}\text { All patients } \\
(\mathrm{N}=903)\end{array}$ & $\begin{array}{l}\text { Survived with } \\
\text { Full Recovery }\end{array}$ & $\begin{array}{l}\text { Survived with } \\
\text { Health } \\
\text { Complication }\end{array}$ & Death \\
\hline Type of & & & & \\
\hline Poisoning & & $860(95.2)$ & $27(3.0)$ & $16(1.8)$ \\
\hline T36 & $12(1.3)$ & $12(1.3)$ & o (o.o) & o (o.o) \\
\hline T37 & $4(0.4)$ & $4(0.4)$ & $\mathrm{o}(0.0)$ & o (o.o) \\
\hline $\mathrm{T}_{3} 8$ & $12(1.3)$ & $12(1.3)$ & $\mathrm{o}(0.0)$ & $\mathrm{o}(0.0)$ \\
\hline $\mathrm{T} 39$ & $322(35.7)$ & $313(34.7)$ & $9(1.0)$ & $\mathrm{o}(0.0)$ \\
\hline $\mathrm{T} 40$ & $20(2.2)$ & $18(2.0)$ & $\mathrm{o}(0.0)$ & $2(0.2)$ \\
\hline $\mathrm{T} 42$ & $37(4.1)$ & $37(4.1)$ & $\mathrm{o}(0.0)$ & $\mathrm{o}(0.0)$ \\
\hline $\mathrm{T} 43$ & $34(3.8)$ & $34(3.8)$ & o (o.o) & o (o.o) \\
\hline $\mathrm{T} 44$ & $41(4.5)$ & $38(4.2)$ & $3(0.3)$ & o (0.0) \\
\hline $\mathrm{T} 45$ & $20(2.2)$ & $O(2.2)$ & o (o.o) & o (0.0) \\
\hline $\mathrm{T} 46$ & $17(1.9)$ & $16(1.8)$ & $\mathrm{o}(0.0)$ & $1(0.1)$ \\
\hline $\mathrm{T} 47$ & $20(0.6)$ & $\mathrm{o}(0.6)$ & $\mathrm{o}(0.0)$ & o (0.0) \\
\hline $\mathrm{T} 48$ & $19(2.1)$ & $\mathrm{O}(2.1)$ & o (o.o) & o (o.o) \\
\hline $\mathrm{T} 49$ & $5(0.6)$ & o (o.6) & o (o.o) & o (o.o) \\
\hline $\mathrm{T}_{50}$ & $7(0.8)$ & $7(0.8)$ & $\mathrm{o}(0.0)$ & o (0.0) \\
\hline $\mathrm{T}_{51}$ & $34(3.8)$ & $30(3 \cdot 3)$ & $\mathrm{o}(0.0)$ & $4(0.4)$ \\
\hline $\mathrm{T}_{52}$ & $17(1.9)$ & $\mathrm{o}(1.6)$ & $2(0.2)$ & $1(0.1)$ \\
\hline $\mathrm{T} 54$ & $71(7.9)$ & $70(7.8)$ & $1(0.1)$ & $\mathrm{o}(0.0)$ \\
\hline T55 & $26(2.9)$ & $26(2.9)$ & o (o.o) & o (o.o) \\
\hline $\mathrm{T} 56$ & $2(0.2)$ & $2(0.2)$ & $\mathrm{o}(0.0)$ & o (0.0) \\
\hline $\mathrm{T} 58$ & $6(0.7)$ & $\mathrm{o}(0.7)$ & o (o.0) & o (0.0) \\
\hline $\mathrm{T} 59$ & $7(0.8)$ & $7(0.8)$ & o (o.o) & o (0.0) \\
\hline T6o & $97(10.7)$ & $79(8.7)$ & $10(1.1)$ & $8(0.9)$ \\
\hline T63 & $75(8.3)$ & $73(8.1)$ & $2(0.2)$ & o (0.0) \\
\hline T64 & $1(0.1)$ & $1(0.1)$ & o (0.0) & o (0.0) \\
\hline T65 & $12(1.3)$ & $12(1.3)$ & $\mathrm{o}(0.0)$ & $\mathrm{o}(0.0)$ \\
\hline
\end{tabular}

Note: All values are reported as no (\%) unless otherwise noted. 


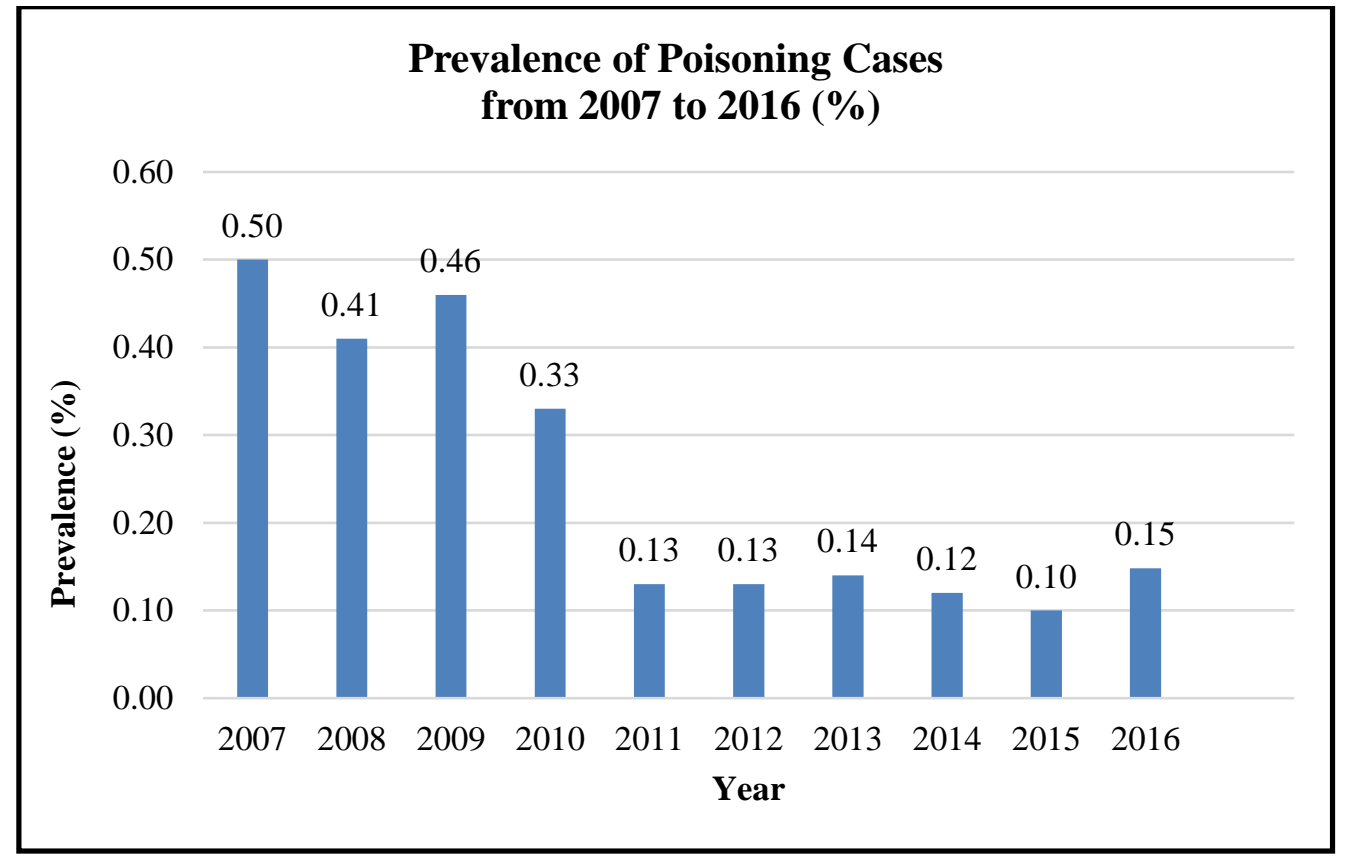

Figure 4. Prevalence of Poisoning Cases from 2007 to 2016

Results showed that the prevalence rate for poisoning cases was $0.22 \%$ with female as the leading gender predominantly cases related to the age group of 18-29 years old. Malay dominated the study while intentional poisoning was predominant. Non-opioids were the most frequent type of poisoning occurred and activated charcoal was the most common antidote used.

The prevalence of poisoning in this study was $0.22 \%$, which is lower compared to another local study which is $0.43 \%$ (Rajasuriar et al., 2007) and it is within the range of 0.16$4.05 \%$ from those reported in studies of oversea countries (Clark, Murray and Ray, 2011) (Moghadamnia and Abdollahi, 2002) (Yang et al., 1996) (Litovitz et al., 2001) (Tagwireyi, Ball and Nhachi, 2002). The wide range of this value most probably because of the difference in reporting technique used to generate this data.

In this ten-year study period, poisoning in females outnumbered male, a finding which is similar to local studies whereby females between the ages of 21 to 30 years old has the preponderance of poisoning admission cases (Rajasuriar et al., 2007) (Teo GS, Teh LC, 2008). Our findings revealed a higher incidence of poisoning in females than in males with female to male ratio of 1.48 , which are similar to several other studies done in other countries with female to the male ratio between ranges of 0.88 to 1.77 (Tufekci, Curgunlu and Sirin, 2004) (Lee et al., 2008) (Hanssens, Deleu and Taqi,
2001) (Fathelrahman, Ab Rahman and Mohd Zain, 2005) (Chirasirisap et al., 1992) (Dash Shreemanta Kumar et al., 2005). Depression is the main risk factor that contributes to suicide attempts and females experience two times more likely than males (Chaudron, L. and Caine, 2004). In this study, most of the patients were from the age group of 18-29 years old. The age distribution for poisoning cases around the world shows a similar pattern (Tufekci, Curgunlu and Sirin, 2004) (Lee et al., 2008) (Chirasirisap et al., 1992). Although there is no particular reason behind this data, social media and usage of internet have increased significantly, data from Journal of Pediatrics United States of America shows that there is a notable increase of the rate of young adults who have attempted suicide by selfpoisoning from 2011 to 2018. In term of race group, most of the poisoning admissions were Malay, followed by Indian and then Chinese.

Intentional poisoning was predominant and more common compared to accidental poisoning. A local study also reported that intentional poisoning was more common in both male and female gender compared to accidental poisoning and male subjects were preponderance in accidental poisoning (Rajasuriar et al., 2007). These results were similar to other oversea studies (Lee et al., 2008) (Tsirigotis, Gruszczynski and Tsirigotis, 2011). Poisoning by non-opioid analgesics is top charted in this study. This data 
was similar to both Profile of Poisoning Admissions in Malaysia 2017 and Poison Statistics National Data 2016 of U.S. Poison Control Centers (Rajasuriar et al., 2007) (U.S. Poison Control Centers, 2016). This is related to the easy availability of non-opioid analgesics over the counter. Poisoning by pesticide is the second highest in this study and had the highest fatality rate. In Malaysia, pesticide is controlled by the Pesticide Act 1976 (Act 167, 1976). However, the purchasing of pesticide was not governed by this law, and anyone can buy pesticide freely in Malaysia. The medical management of acute pesticide poisoning is difficult and till date, there are no clear-cut evidence-based guidelines for the best management of organophosphate poisoning (Van Hoving, Veale and Müller, 2011).

In this ten-year study, 95.2\% of patients survived with full recovery. Similar survival rate was reported by Clark et al. (2011), which documented a great majority (96\%) of patients survived. The availability of 24-hour operating poison call centre, National Poison Centre of Malaysia provides a useful resource for healthcare providers in guiding them on management decisions for the patients who may have been exposed to a variety of toxic agents. Although Malay ethnicity had the leading number in term of poisoning admissions interestingly, they had the lowest fatality rate. Indian ethnicity had the highest fatality rate which was similar to the data in Profile of Poisoning Admissions in Malaysia 2017. In Malaysia, there was a study conducted to investigate completed suicide, and the result shows that the highest incidence occurred among Indian (Hayati et al., 2004) (Kasinathan NADESAN, MRCPath, 1999). This result associated with their accessibility to agrochemicals, as well as their unsafe handling of these substances (Rajasuriar et al., 2007).

Although this is a small study, the outcome measure is meaningful in providing sufficient justification in need of self-injury prevention education and training among public and healthcare providers respectively. The major limitation is that each ICD10 code and sub-code may represent more than one number of substances. Thus, it is difficult to obtain the specific substance that was involved in poisoning related cases. Diagnosis of patients also may be classified wrongly which may result in incomplete data collection.

\section{CONCLUSION}

This review of Serdang Hospital poisoning admissions managed to highlight important issues, such as the Indian population has a higher fatality rate as compared to others. Pesticides and non-opioid analgesics were the highest substances related to poisoning cases. Revealing this information of poisonings will provide an essential idea for the recognition of areas where training, education and maybe even legal interventions may be required. However, further research is needed to provide more insight into the specific substances that are involved

\section{ACKNOWLEDGEMENT}

We would like to thank the director-general of the Ministry of Health Malaysia for permission to publish this report. We would like to express our sincere gratitude for everyone who was involved directly or indirectly in helping us to complete this study.

\section{REFERENCES}

Ab Rahman, A.F. 2002, 'Drug and chemical poisoning admissions at a teaching hospital in Malaysia', Human \& Experimental Toxicology, vol 21, no. 7, pp. 377-381. doi: 10.1191/o960327102ht260oa.

Act 167, L. of M. 1976, Laws Of Malaysia, Act 167, Plant Quarantine Act 1976.
Buckle, N.A. et al. 2004, 'Where is the evidence for treatments used in pesticide poisoning? Is clinical toxicology fiddling while the developing world burns?', $J$ Toxicol Clin Toxicol.

Centers for Disease Control and Prevention (CDC) 2015, Web-based Injury Statistics Query and Reporting System 
(WISQARS)', available at: http://www.cdc.gov/injury/ wisqars/index.html.

Chaudron, L. and Caine, E. 2004, 'Suicide among women: A critical review', Women's Health, vol. 59, no. 2, pp. 125134 .

Chirasirisap, K. et al. 1992, 'A study of major causes and types of poisoning in Khonkaen, Thailand', Veterinary and Human Toxicology, vol. 34, no. 6, pp. 489-492.

Chowdhury, F. et al. 2011, 'Acute poisoning in southern part of Bangladesh - The case load is decreasing. Bangladesh', Med Res Counc Bull, vol. 37, pp. 61-5.

Clark, D., Murray, D. B. and Ray, D. 2011, 'Epidemiology and outcomes of patients admitted to critical care after selfpoisoning', Journal of the Intensive Care Society, vol. 12, no. 4, pp. 268-273.

doi: 10.1177/175114371101200405.

Dash Shreemanta Kumar et al. 2005, 'Sociodemographic profile of poisoning cases', Journal of Indian Academy of Forensic Medicine, vol. 27, no. 3, pp. 133-138.

David Gunnell, Michael Eddleston, M. R. P. \& F. K. 2007, 'The global distribution of fatal pesticide self-poisoning', $B M C$ Public Health, vol. 7, p. 357. http://doi.org/10.1186/1471-2458-7-357.

Fathelrahman, A. I., Ab Rahman, A. F. and Mohd Zain, Z. 2005, 'MS 04-044: demographic features of drug and chemical poisoning in northern Malaysia.', Clinical toxicology (Philadelphia, Pa.), vol. 43, no. 2, pp. 89-94.

Gunnell D, E. M. 2003, 'Suicide by intentional ingestion of pesticides: a continuing tragedy in developing countries.', Int $J$ Epidemiol, vol. 32, pp. 902-9.

Hanssens, Y., Deleu, D. and Taqi, A. 2001, 'Etiologic and demographic characteristics of poisoning: a prospective hospital-based study in Oman', Journal of toxicology. Clinical toxicology, vol. 39, no. 4, pp. 371-380.

Hayati, A. N. et al. 2004, 'The pattern of completed suicides seen in Kuala Lumpur General Hospital 1999', The Medical Journal of Malaysia, vol. 59, no. 2, pp. 190-198.

Van Hoving, D. J., Veale, D. J. H. and Müller, G. F. 2011, 'Clinical Review: Emergency management of acute poisoning', African Journal of Emergency Medicine, vol. 1, no. 2 , pp. 69-78.

doi: 10.1016/j.afjem.2011.07.006.

Kasinathan NADESAN, MRCPath, F. 1999, Pattern of suicide: a review of autopsies conducted at the University Hospital, Kuala Lumpur, Department of Pathology, Faculty of Medicine, University of Malaya, Kuala Lumpur, Malaysia.
Lee, H.-L. et al. 2008, 'Presentations of patients of poisoning and predictors of poisoning-related fatality: findings from a hospital-based prospective study', BMC Public Health, vol. 8, p. 7 . doi: 10.1186/1471-2458-8-7.

Litovitz, T. L. et al. 2001, '2000 Annual report of the American Association of Poison Control Centers Toxic Exposure Surveillance System', The American Journal of Emergency Medicine, vol. 19, no. 5, pp. 337-395.

doi: 10.1053/ajem.2001.25272.

Masiran, R. et al. 2017, 'Rates and Profiles of Self-Harm Presenting to Malaysian General Hospitals: Data from the Ministry of Health in 2011', Mal $J$ Med Health Sci Malaysian Journal of Medicine and Health Sciences, vol. 13, no. 2, pp. 39-45.

Moghadamnia, A. A. and Abdollahi, M. 2002, 'An epidemiological study of poisoning in northern Islamic Republic of Iran', Eastern Mediterranean health journal = La revue de sante de la Mediterranee orientale $=$ alMajallah al-sihhiyah li-sharq al-mutawassit, vol. 8, no. 1, pp. 88-94.

Rajasuriar, R. et al. 2007, 'Profile of poisoning admissions in Malaysia', Human \& Experimental Toxicology, vol. 26, no. 2, pp. 73-81. doi: 10.1177/0960327107071857.

Silvia S. Canetto, D. L. 1998, 'Gender, Culture, and Suicidal Behavior', Transcultural Psychiatry - TRANSCULT PSYCHIATRY, no .35, pp. 163-190.

10.1177/136346159803500201.

Tagwireyi, D., Ball, D. E. and Nhachi, C. F. B. 2002, 'Poisoning in Zimbabwe: a survey of eight major referral hospitals', Journal Of Applied Toxicology : JAT, vol. 22, no. 2, pp. 99-105.

Teo GS, Teh LC, L. J. 2008, Parasuicide And Suicide: Demographic Features And Changing Trend Among Cases In Hospital Sungai Bakap 2001-2005, vol. 17.

Tsirigotis, K., Gruszczynski, W. and Tsirigotis, M. 2011, 'Gender differentiation in methods of suicide attempts', Med Sci Monit, vol. 17, no. 8, pp. 65-70. doi: 10.12659/MSM.881887.

Tufekci, I. B., Curgunlu, A. and Sirin, F. 2004, 'Characteristics of acute adult poisoning cases admitted to a university hospital in Istanbul', Human \& Experimental Toxicology, vol. 23, no. 7, pp. 347-351.

doi: 10.1191/o960327104ht46ooa.

U.S. Poison Control Centers 2016, Poison Statistics National Data 2016, United State. 
W. Wananukul, C. Sriapha, A. Tongpoo, U. Sadabthammarak, S. Wongvisawakorn, and S. K. 2007, 'Human poisoning in Thailand: the Ramathibodi Poison Center's experience (2001-2004), Clinical toxicology, vol. 45 , no. 5 , pp. 582-588.

WHO 2012, Poisoning prevention and management.

Yang, C. C. et al. 1996, 'Taiwan National Poison Center: epidemiologic data 1985-1993.', Journal of Toxicology, vol. 34 , no. 6, pp. 651-663. 